\title{
The effect of menstrual cycle on anaerobic power and jumping performance
}

\author{
Aysegul Yapici-Oksuzoglu ${ }^{\mathrm{ABCDE}}$, Halit Egesoy ${ }^{\mathrm{DE}}$ \\ Pamukkale University Faculty of Sport Science, Turkey
}

Authors' Contribution: A - Study design; B - Data collection; C - Statistical analysis; D - Manuscript Preparation; E- Funds Collection.

$\begin{array}{ll}\begin{array}{l}\text { Abstract } \\ \text { Background } \\ \text { and Study Aim }\end{array} & \begin{array}{l}\text { There has been a significant increase in the participation levels of women in competitive sports in recent } \\ \text { years. This has contributed to the increase of research on women's participation in sports and their health. } \\ \text { The aim of this study is to investigate the effect of the menstrual cycle on anaerobic power and jumping } \\ \text { performance. } \\ \text { In this study, } 15 \text { female athletes between the ages of 18-24, who have a regular menstrual cycle for the }\end{array} \\ \text { Methods } & \begin{array}{l}\text { last } 6 \text { months. They have not used any hormone preparations, have not received any medical support in } \\ \text { the last month. They are healthy and actively engaged in sports in university teams (basketball, futsal, } \\ \text { volleyball) participated voluntarily. Wingate Anaerobic Power Test and Active Jumping Test applied to } \\ \text { athletes during their menstrual phases (second day of the menstruation period) and follicular phases } \\ \text { (14th day of the menstruation period). In the statistical analysis of the data, descriptive analyses of test } \\ \text { measurements of athletes were calculated as mean and standard deviation. Whether there is a significant } \\ \text { difference between the measurements taken on two different days was analyzed using the t-test in } \\ \text { dependent groups. } \\ \text { It was determined that the anaerobic power and active jump performances of the participants had an } \\ \text { effect on peak power, fatigue index and active jump performance between day } 2 \text { and day } 14 \text { values. Also, } \\ \text { there was a statistically significant difference between these values (p<0.05). }\end{array} \\ \text { Results } & \begin{array}{l}\text { This situation can be explained as a result of the hormonal changes in the menstrual period of the athletes } \\ \text { and the effects of psychological factors specific to this period. } \\ \text { menstruation, performance, sport, anaerobic power, active jumping. }\end{array} \\ \text { Conclusions: } & \end{array}$

\section{Introduction}

Women have a different structure compared to men with their physiological, anatomical, psychological and special conditions. The difference in these structures greatly affects the sportive performance of both breeds. The biggest physiological difference that separates women from men is the menstrual cycles under the control of the hormonal system [1]. In addition, when both sexes are examined in terms of anatomical structure, there is a $5-10 \%$ difference between them, while this rate varies around 10$20 \%$ in terms of their physiological structures [2].

In recent years, there has been a significant increase in the participation levels of women in competitive sports. This situation has contributed to the increase of research on women's participation in sports and their health. According to researches, it has been stated that varying hormone levels within the menstrual cycle can affect sports performance [3-6].

Female athletes who have regular menstrual cycles do not need to correct their menstrual bleeding for maximal performance in sports branches that require strength and power, and in sports where high levels of aerobicanaerobic capacity are required. It is very important to organize mental and physical functions in a balanced way for maximal physical performance. Since the effects of menstruation on sportive performance are remarkable, there have been many studies in the literature examining (c) Aysegul Yapici-Oksuzoglu, Halit Egesoy, 2021 doi:10.15561/26649837.2021.0605 the relationship between menstruation and sports [7-11].

Studies on the subject in the literature have shown that menstruation does not have a great effect on the organism and women can easily participate in sports activities. In fact, it has been observed that many female athletes performed successfully and achieved significant degrees during their menstrual periods [12] In addition, it is known that irregularities of the menstrual cycle are often seen in endurance athletes [13]. In a study conducted on adolescent athletes, it was reported that menstrual disorders are quite common [14].

In the findings of these studies, it was determined that it was not revealed exactly whether menstruation affects sports performance in women. It is very important to determine how the menstrual period affects women's sports performance and their capacity to use motor characteristics. In this context, this research was conducted to investigate the effect of the menstrual cycle on anaerobic power and jumping performance.

\section{Material and Methods}

\section{Research Group}

In this study, 15 female athletes between the ages of 18-24, who have a regular menstrual cycle for the last 6 months. They have not used any hormone preparations, have not received any medical support in the last month. They are healthy and actively engaged in sports in university teams (basketball, futsal, volleyball) 
participated voluntarily.

Prior to the study, 18 June 2021 (Decision number: 60116787-020-64733) ethics committee approval was obtained from Pamukkale University Non-Invasive Clinical Research Ethics Committee.

Participants were given detailed information about the risks that may be encountered in the study, and the voluntary consent form was read and signed. In addition, participants were asked to sleep for at least 8 hours before each test, to avoid intense physical activity the day before and on the test day, and to quit alcohol and caffeine intake 24 hours before each test.

\section{Procedure}

On which day of the menstrual cycle of the subjects, the subjects were asked verbally in advance and the measurements were planned based on the information provided by the subjects. In this study the measurements were taken in the menstrual phase, which is the second day of the menstruation period, and the ovulation phase (ovulation period), which is the 14th day. The menstrual calendars of the subjects were recorded one month before the measurement started.

\section{Exclusion Criteria}

* Using a menstrual regulator,

* Disabled or sick on the day of measurement,

* Participants with suspected pregnancy were excluded from the study.

Data Collection Tools

\section{Anthropometric Measurements}

Participants' height was measured with a wall-mounted stadiometer (Holtain, England), which can measure with an accuracy of $0.1 \mathrm{~cm}$, and body weight with an electronic scales (Tanita TBF 401A, Japan) that can measure with an accuracy of $0.1 \mathrm{~kg}$.

\section{Performance Tests}

Active Jumping Test

A total of 8 minutes of warm-up protocol was applied to the participants including 5 minutes of lowtempo warm-up and 3 minutes of dynamic flexibility movements for lower extremities before the test. Later, the active jumping performances of the participants were measured with Smart Jump. The athletes climbed on the mat in light sports clothing (tights and T-shirt) and made a quick downward slump from the upright position, jumped upward with maximum force and were placed back on the mat. This jumping was repeated 3 times. The best and average jump height and the best and average hovering times were read and recorded from the computer program as the hops time in the air in milliseconds (ms) and height in centimeters $(\mathrm{cm})$.

Wingate Anaerobic Power Test

A pre-test warm-up protocol was applied to the participants. After the participants sit on the bicycle ergometer, the appropriate sitting height was set. Warmup included pedaling at 60-70 RPM (RPM) for 4 minutes. The participant applied 3-second maximal pedaling protocols 1 minute 30 seconds after the beginning of this warm-up period and 2 minutes and 30 seconds later. By observing the maximum RPM speed of the participant at these maximal pedal speeds, the required saddle release pedal speed for the test was determined. After the warmup was finished, the participants were given a 5-minute recovery period. Then, when the participants reached the maximal pedal speed within the first 5 seconds, the weight seat was automatically released and they pedal at the maximum speed on the bicycle ergometer against the predetermined constant load for 30 seconds to provide the highest mechanical power. During the test applied, measurements were made automatically every five seconds at six equal time intervals and the relative power data were recorded as maximum anaerobic power (W $/ \mathrm{kg}$ ), average anaerobic power $(\mathrm{W} / \mathrm{kg}$ ) and minimum anaerobic power $(\mathrm{W} / \mathrm{kg})$.

Statistical Analysis

SPSS 22.0 for Windows package program was used in the analysis of the data obtained. Descriptive analyzes of the participants' basic characteristics were calculated as mean and standard deviation. Whether the data showed normal distribution was evaluated using the Shapiro-Wilk test. Whether there is a significant difference between the measurements taken on two different days was analyzed using the t-test in dependent groups. The level of significance was set at $\mathrm{p}<0.05$.

\section{Results}

Descriptive characteristics of the participants are shown in Table 1.

As a result of the measurements made, it was determined that wingate anaerobic test and active jump performances of the participants had an effect on peak power, fatigue index and active jump performance between day 2 and day 14 values. There was a statistically significant difference between these values $(p<0.05)$. In the study, when the performance values in different phases of the menstrual cycle were compared, it was found that the anaerobic performances and jumping performances of female athletes were higher on the 14th day, that is, during the ovulation period (Table 2).

Table 1. Descriptive characteristics of the participants

\begin{tabular}{lllll}
\hline Variables & N & Mean \pm Sd & Min. Value & Max. Value \\
\hline Age (years) & 15 & $21.27 \pm 2.05$ & 18 & 24 \\
Body weight $(\mathrm{kg})$ & 15 & $60.40 \pm 5.88$ & 50,20 & 72,50 \\
Height $(\mathrm{cm})$ & 15 & $167.40 \pm 4.69$ & 160,44 & 175,78 \\
\hline
\end{tabular}


Table 2. Anaerobic power and jump performance menstrual phase difference analysis table

\begin{tabular}{|c|c|c|c|c|}
\hline & Parameters & Mean \pm Sd & $\mathbf{t}$ & $\mathbf{p}$ \\
\hline \multirow{11}{*}{$\begin{array}{l}\frac{1}{0} \\
3 \\
0 \\
0 \\
\frac{0}{0} \\
\frac{0}{0} \\
\frac{0}{0} \\
\frac{0}{0} \\
\frac{1}{2}\end{array}$} & Peak Power (W) $2^{\text {nd }}$ day & $873,96 \pm 98,29$ & \multirow{3}{*}{$-2,80$} & \multirow{3}{*}{$0,001^{*}$} \\
\hline & & & & \\
\hline & Peak Power (W) $14^{\text {th }}$ day & $950,46 \pm 83,31$ & & \\
\hline & Average Power (W) $2^{\text {nd }}$ day & $612,45 \pm 88,86$ & \multirow[b]{2}{*}{$-1,33$} & \multirow[b]{2}{*}{0,20} \\
\hline & & & & \\
\hline & Min Power (W) $2^{\text {nd }}$ day & $344,90 \pm 98,56$ & \multirow{3}{*}{$-1,79$} & \multirow{3}{*}{0,09} \\
\hline & & & & \\
\hline & Min Power (W) $14^{\text {th }}$ day & $399,89 \pm 71,58$ & & \\
\hline & Fatigue Index (\%) $2^{\text {nd }}$ day & $60,73 \pm 9,46$ & \multirow{3}{*}{3,19} & \multirow{3}{*}{$0,01^{*}$} \\
\hline & & & & \\
\hline & Fatigue Index (\%) $14^{\text {th }}$ day & $51,19 \pm 10,82$ & & \\
\hline \multirow{3}{*}{ 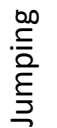 } & Active Jumping $(\mathrm{cm}) 2^{\text {nd }}$ day & $25,67 \pm 4,92$ & \multirow{3}{*}{$-3,80$} & \multirow{3}{*}{$0,00^{*}$} \\
\hline & & & & \\
\hline & Active Jumping $(\mathrm{cm}) 14^{\text {th }}$ day & $27,39 \pm 5,82$ & & \\
\hline
\end{tabular}

$(p<0,05)$

\section{Discussion}

The menstrual cycle affects many parameters in metabolic, cardiovascular and respiratory aspects besides athletic performance due to the changes it causes in hormonal structure. Since there are many factors that affect athletic performance, researchers have also done a lot of research on performance changes during menstrual periods. When the studies in the literature are examined, it is seen that the findings of the research examining the relationship between sportive performance and menstrual cycle periods are contradictory [15]. In some studies, there was no significant change in sports performance parameters during menstruation [16-18], on the other hand, in some studies, it was determined that there was an increase or decrease in sports performance elements during this period [19-21].

According to the findings of the study, it was determined that wingate anaerobic test and active jump performances of the participants had an effect on peak power, fatigue index and active jump performance between day 2 and day 14 values and there was a statistically significant difference between these values $(p<0.05)$. In the study, when the performance values in different phases of the menstrual cycle were compared, it was found that the anaerobic performances and jumping performances of female athletes were higher on the 14th day, that is, during the ovulation period.

Looking at the studies parallel to the findings of our study, Masterson [22] found a difference in the wingate anaerobic power test performed in the follicular phase and luteal phase in his study on 32 college athletes in terms of anaerobic capacity between phases and the maximum power values they can produce. According to the test results, anaerobic capacity and maximum power values were higher in the follicular phase compared to the luteal phase. In a similar study by Karacan [23] it was reported that premenstrual syndrome, in which physical, psychological and behavioral changes are experienced in the second half of the menstrual cycle three days before menstruation, negatively affects attention, concentration, motivation, speed and quickness, which are among the determinants of performance. Colakoglu et al. [24] investigated the relationship between exercise-menstruation and training age-menstrual cycle pattern in a survey they conducted on 56 active female volleyball players, and as a result, they found that exercise did not affect menstruation and that menstruation psychologically affected sports activity. Karacan et al. [25] in their studies investigating the relationship between menstruation and different branches of football, basketball, handball and field hockey, among 133 women athletes from the Turkish First League and Turkish Super League, it was stated that menstruation physically affected sportive activity as well as sports activity. Also reported that it affects the menstrual cycle. Kucuk and Ozgider [26] in the survey they conducted on 72 volunteer women volleyball players, the athletes' menstruation; They reported that it affected their daily life and physical performance. In a study conducted by Akkus [27] on athletics and volleyball athletes, it was found that the strength, speed and endurance performances of athletes differ in different stages of the menstruation period, and these changes were found to be at a statistically significant level. Smith et al. [28] showed that menstruation was affected by high intensity exercises in the responses to exercises of different intensity in 3 different periods of menstruation. Aras et al. [29] examined anaerobic power 
values according to the phases of the menstrual cycle in their study. For the 9 volunteers who participated, they found that the anaerobic power values did not change in the follicular, ovulation and luteal phases of the menstrual cycle.

There are studies in the literature that do not parallel our study findings. In a study conducted by Higgs and Robertson [30] it was found that there is no change in the sportive performance of female athletes before and during menstruation. Ertas and Ersoz [31] reported in their study on 28 female athletes with 14 regular and 14 irregular menstruations, and the best degrees of athletes were at the beginning of menstruation. Cakmakc1 et al. [2] applied wingate test to female university students on the 2 nd and 14th day of their menstrual cycle and reported that anaerobic performance obtained in menstruation and follicular phases was not different as a result of the research. Dolek and Ersoz [32] in their study on swimmers, showed that athletes with regular menstruation periods are best 25 meters They reported that they demonstrated their swimming performances on the 2nd and 15th day of their menstrual cycle, respectively, and the worst degrees occurred on the 26th day of the cycle, and there was a statistically significant difference between the results. In another study conducted by Bushman et al. [33] anaerobic power in moderately active women between menstrual period and luteal period after the wingate test in both normal menstrual cycles $(n=7)$ and oral contraceptive users $(n=17)$ It has been determined that there is no difference. Tsampoukos et al. [34] in their study on 8 healthy female athletes, reported that the mean peak power and mean power values did not differ statistically between phases. Hazır et al. [35] found no effect of menstruation on repetitive sprint performance and recovery rate in the repetitive sprint test and recovery rate measurements they performed in the midfollicular phase and luteal phase on 11 female athletes with regular menstruation. In the study conducted by Stefanovsky et al. [36] on judo athletes, the participants were applied the wingate test and their performance values in different phases of the menstrual cycle were compared. It has been reported that there is no statistically significant difference between the performance values. Moraleda et al. [16] in their study on 13 female triathletes, performed half squats with $50 \%$ of their $1 \mathrm{RM}$ on athletes. It has been reported that the performances of the athletes in 3 different menstrual cycles did not make a significant difference. In a study conducted by Guler [37] on volleyball players, it was reported that the menstrual cycle did not have any effect on the flexibility, muscle strength, anaerobic power and sprint performances of the athletes. The period of menstruation, physiological changes in body weight, edema in the abdomen, wrists and ankles, pain in the abdomen and waist area, psychological anxiety, irritability, minor depressive states, and mental depressions are clinical symptoms of premenstrual syndrome. Physiologically and psychologically negative effects are thought to affect performance negatively [23].

\section{Conclusions}

As a result, it can be said that physiological changes during menstruation should be known by trainers and it should be taken into consideration that these changes may affect sportive performance. In addition, in new studies on the subject; the number of phases measured, the number of similar tests and subjects can be increased. In other branches where the anaerobic energy system is dominant, the measurement can be made by applying the same test protocol and the results can be compared.

\section{Acknowledgments}

The author would like to thank all players for their willingness to participate in this study.

\section{Conflicts of Interest}

The authors state no conflicts of interest.

\section{References}

1. Sevim Y. Training Information. 7th Edition. Ankara: Nobel Publishing; 2002.

2. Cakmakcı E, Sanioglu A, Patlar S, Cakmakcı O, Cinar V. The effect of menstruation on anaerobic power, Journal of Spormetre, 2005; 3 (4): 145-149. https://doi.org/10.1501/Sporm_0000000054

3. Lebrun CM, Rumball JS. Relationship between athletic performance and menstrual cycle. Curr Womens Health Rep. 2001; 1(3): 232-240.

4. Lebrun CM, Joyce SM, Constantini NW. Effects of female reproductive hormones on sports performance, In Endocrinology of Physical Activity and Sport. Humana Press, 2013; 281-322. https://doi.org/10.1007/978-1-62703-314-5_16

5. Lepers R, Maffiuletti NA. Age and gender interactions in ultraendurance performance: insight from the triathlon, Medicine and Science in Sports and Exercise, 2011; 43(1): 134-139. https://doi.org/10.1249/MSS.0b013e3181e57997

6. PereiraA,IzquierdoM,SilvaAJ,CostaAM,BastosE, GonzálezBadillo JJ, Marques MC. Effects of high-speed power training on functional capacity and muscle performance in older women, Experimental gerontology, 2012; 47(3): 250-255. https://doi.org/10.1016/j.exger.2011.12.010

7. Constantini NW, Dubnov G, Lebrun CM. The menstrual cycle andsportperformance.ClinSportsMed.Apr,2005;24(2):51-82. https://doi.org/10.1016/j.csm.2005.01.003

8. Dusek T. Influence of high intensity training on menstrual cycle disorders in athletes, Croat Med J, 2001; 42(1): 79-82.

9. Janse DE, Thompson MW, Chuter VH, Silk LN, Thom JM. Exercise performance over the menstrual cycle in temperate and hot, humid conditions. Medicine and Science in Sports and Exercise, 2012; 44(11): 2190-2198. https://doi.org/10.1249/MSS.0b013e3182656f13

10.Roupas ND, Georgopoulos NA. Menstrual function in sports, Hormones, 2011; 10(2): 104-116. https://doi.org/10.14310/horm.2002.1300

11. Wojtys EM, Huston LJ, Boynton MD, Spindler KP, Lindenfeld TN. The effect of the menstrual cycle on anterior cruciate ligament injuries in women as determined by hormone levels, The American Journal of Sports Medicine, 2002; 30(2): 182-188. 
https://doi.org/10.1177/03635465020300020601

12.Cavlica B. The effect of menstrual phases on aerobic, anaerobic capacity, pain threshold and pain tolerance in elite volleyball players, Master Thesis, Institute of Health Sciences, Celal Bayar University, 2006, Manisa.

13.Oral E, Aydoğan B. Primary Amenorrhea. Turkish Archives of Pediatrics, 2011; 46(Special Issue): 92-96. https://doi.org/10.4274/tpa.46.44

14.Thein-Nissenbaum JM, Rauh MJ, Carr KE, Loud KJ, McGuine TA. Associations between disordered eating, menstrual dysfunction, and musculoskeletal injury among high school athletes, Journal of Orthopaedic and Sports Physical Therapy, 2011; 41(2): 60-69. https://doi.org/10.2519/jospt.2011.3312

15.Tasmektepligil MY, Agaoglu SA, Turkmen L, Turkmen M. The motor performance and some physical characteristics of the sportswomen and sedentary lifestyle women during menstrual cycle. Science of Martıal Arts, 2010; 6(4): 195203.

16. Moraleda BR, Coso JD, Gutiérrez-Hellín J, Ruiz-Moreno C, Grgic J, Lara B. The influence of the menstrual cycle on muscle strength and power performance, Journal of Human Kinetics, 2019; (68): 123-133. https://doi.org/10.2478/hukin-2019-0061

17.Teixeira ALDS, Fernandes Júnior W, Marques FAD, Lacio MLD, Dias MRC. Influence of different phases of menstrual cycle on flexibility of young women. Revista Brasileira de Medicina do Esporte, 2012a; 18(6): 361-364. https://doi.org/10.1590/S1517-86922012000600002

18.Teixeira ALDS, Júnior WF, Moraes EM., Alves HB, Damasceno VDO, Dias MRC. Effects of menstrual cycle phase on resting heart rate in healthy women, Journal of Exercise Physiology Online, 2012b; 15(4): 47-54.

19.Karp J, Smith CS. Running for women. Champaign, IL: Human Kinetics; 2012.

20.Lemke SM. Neuromuscular performance and the menstrual cycle. [Masters thesis]. Bozeman, Montana: Montana State University; 2007.

21.Perciavalle V, Coco M, Maugeri A, Gurrisi L. Relations between menstrual phase and performance of an intense 1ntermittent actıvity, Acta Medica Mediterranea, 2007; 23(15): 15-20.

22.Masterson G. The impact of menstrual phases on anaerobic power performance in collegiate women. Journal of Strength and Conditioning Research, 1999; 13(4): 325-329. https://doi.org/10.1519/00124278-199911000-00005

23.Karacan S. The effect of menstruation and premenstrual syndrome on some basic motoric properties and physiological parameters in female athletes. [Masters thesis]. Ankara: Gazi University Physical Education Sports High School; 2000.

24.Colakoğlu F, Can B, Ersoz G. Evaluation of menstrual status of female athletes playing in the away Turkish Volleyball 1st League in 2002-2003 season. Gazi Journal of Physical Education and Sport Sciences, 2005; 1: 51-64.
25.Karacan S, Çolakoğlu F, Ersöz G. Evaluation of menstrual status of Turkish elite women athletes in different team sports. Nigde University Journal of Physical Education and Sports Sciences, 2013; 7(2): 2-93.

26.Kucuk S, Ozgider C. Investigation of the effect of menstruation on sportive performance in female volleyball players, 3rd National Sports Sciences Student Congress, 1920 May/2010, Çanakkale; 2010. P. 100-110.

27.Akkus M. Investigation of the effect of menstrual periods on sports performance in women. [Masters thesis]. Sakarya: Sakarya University Institute of Education Sciences; 2014.

28.Smith JR, Brown KR, Murphy JD, Harms CA. Does menstrual cycle phase affect lung diffusion capacity during exercise? Respiratory Physiology \& Neurobiology, 2015;205:99-104. https://doi.org/10.1016/j.resp.2014.10.014

29.Aras D, Arslan E, Atlı A, Sahın FN. Investigation of anaerobic power values in sedentary women according to the phases of the menstrual cycle, Ankara University Faculty of Sports Sciences, Journal of Spormetre, 2016;14:191-8. https://doi.org/10.1501/Sporm 0000000296

30.Higgs SL, Robertson LA. Cyclic variations in perceived exertion and physical work capacity in females. Can. J. Appl. Sport Sci. 1981; (6): 191-196.

31.Ertas B, Ersoz G. The effects of different menstruation periods on selected performance criteria in female swimmers. 7th International Sports Sciences Congress. October/2002, Antalya; 2002. P. 100-105.

32.Dolek BE, Ersoz G. The effects of different menstrual periods on selected performance criteria in young female swimmers, Journal of Spormetre, 2017; 15 (2): 93-100. https://doi.org/10.1501/Sporm 0000000313

33.Bushman B, Masterson G, Nelsen J. Anaerobic power performance and the menstrual cycle: eumenorrheic and oral contraceptive users. J Sports Med Phys Fitness, 2006;46:132-7.

34.Tsampoukos A, Peckham EA, James R, Nevill ME. Effect of menstrual cycle phase on sprinting performance. Eur J Appl Physiol. 2010; 109(4): 659--67. https://doi.org/10.1007/s00421-010-1384-z

35.Hazır T, Akdoğan B, Açıkada C. Lactic acid from blood during repeated sprint performance and active recovery of menstrual cycle phases impact on removal rate. Hacettepe Journal of Sports Sciences, 2011; 22(3): 115-123.

36.Stefanovsky M, Péterova A, Vanderka M, Lengvarsky L. Influence of selected phases of the menstrual cycle on performance in special judo fitness test and wingate test, Acta Gymnica, 2016; 46(3): 136-142. https://doi.org/10.5507/ag.2016.015

37.Guler I. Investigation of the effect of menstruation period on sportive performance of women's volleyball player, African Educational Research Journal, 2020; 8(2): 387-391. https://doi.org/10.30918/AERJ.82.20.068 


\section{Information about the authors:}

Aysegul Yapici-Oksuzoglu; (Corresponding author); https://orcid.org/0000-0003-4243-5507; ayapici@msn.com; Faculty of Sport Science; Pamukkale University, Denizli, Turkey.

Halit Egesoy; https://orcid.org/0000-0003-1347-8647; hegesoy1@hotmail.com; Faculty of Sport Science; Pamukkale University, Denizli, Turkey.

Cite this article as:

Yapici-Oksuzoglu A, Egesoy H. The effect of menstrual cycle on anaerobic power and jumping performance. Pedagogy of Physical Culture and Sports, 2021;25(6):367-372.

https://doi.org/10.15561/26649837.2021.0605

This is an Open Access article distributed under the terms of the Creative Commons Attribution License, which permits unrestricted use, distribution, and reproduction in any medium, provided the original work is properly cited

(http://creativecommons.org/licenses/by/4.0/deed.en).

Received: 05.09.2021

Accepted: 20.10.2021; Published: 30.12.2021 